\title{
Democratizing deliberative systems
}

\author{
JOHN PARKINSON
}

Deliberation occurs in many different kinds of social system; but not all deliberative systems are democratic. Deliberation might occur in enclaves that are cut off from formal decision-makers; it might occur within a limited elite; and the inputs into elite deliberation might be technical-legal ones rather than the reflective preferences of those affected.

As Papadopoulos emphasizes in the Chapter 6, deliberation is just one value among several that drive modern governance. Even if the formal institutions of government are reasonably democratic, there are other systems of power that can pull in different directions and that are resistant to democratic control: the judicial system, the administrative system, the economic system, and so on.

Furthermore, there may be features of the systemic account of deliberation that weaken its democratic credentials - that weaken the ability of the demos to fight back against economic, technical, or juridical power. For example, if Chambers (Chapter 3) is right, and social science surveys can count as valid inputs in a deliberative system, then how do real, flesh and blood people get their voices heard? If the processes by which a system gives voice to its citizens becomes yet another preserve of technical experts, then public debates can become battles over who possesses the right technology rather than the substantive merits of cases made in less technically sophisticated ways (Mort et al. 1996; Parkinson 2004). In such settings, public participation can easily become passive rather than active, the result of a random selection process or a privilege bestowed by the powerful, not a right that one can claim against the powerful (cf. Cooke and Kothari 2001; Gaventa 2006). 
This would be ironic indeed. As was pointed out in the introduction, one of the key motivations behind the systemic turn in deliberative theory is to put the democracy back into deliberation because of concerns about the democratic possibilities of isolated minipublics both in principle and in practice in modern technocratic states. Indeed, it has been thought for some time now that the deliberative and democratic desiderata pull in opposite directions, with deliberative criteria being maximized in smallscale settings and the democratic being maximized in large. While Goodin and Dryzek (2006) have been cited as frequently presenting reasons to be cheerful, Papadopoulos presents a more complex picture in which deliberation becomes yet another tool for exclusion. This book has been focused on rethinking the deliberative criteria to see how they can be made to work at the large scale. But we should not just assume that the democratic criteria hold too.

The aim of this concluding chapter is, therefore, to ask whether it really makes sense to speak not just of macro deliberation, but of macro deliberative democracy. It analyses this question in two broad themes - democratizing rationality and the question of decisiveness - and while it focuses on the answers that the volume's contributors provide, it does not restrict itself to those. Along the way, it raises four caveats to do with the way that deliberative systems are likely to work in context, especially the context of the states under the influence of Papadopoulos's administrative imperatives, features of mediatized communication systems, changes in the nature of citizenship, and two political features that still should play more of a role in deliberative scholarship than they often do: power and interests. The analysis gives cautious support for the idea that a democratic deliberative system is workable in principle, but with some important specifications about procedures. Whether the empirical objections can be overcome is another matter, and the chapter ends with a call to analytic and empirical action.

The conclusions are ones that echo this volume's overall pluralism: there are many different possible configurations of sites, actors, and roles that will achieve deliberatively democratic outcomes, but 'many different' is not the same as saying 'infinite'. What is recommended here is what I call a 'stepped pluralism', coupled to a fluid, relationship-based account of representation, more demanding criteria for deliberative justification at the empowered end of deliberative systems, institutional referees, and a central role for decisiveness.

\section{Public reason and equal treatment}

The purpose of a deliberative system remains to place public reasoning at the heart of politics, although what public reason demands has changed in 
important ways over the last decade of deliberative scholarship. Christiano (Chapter 2) pushes the hardest line on this point, arguing that the purpose of a deliberative system is to produce epistemically better outcomes, and the best means to achieve that is to have a division of labour between experts and citizens: citizens providing the basic aims of society and experts debating the means. However, citizens' legitimate concerns are often about means, not just ends. Citizens very often agree that they do not want riots and looting in the streets, to take an example highly salient in the UK at the time of writing, but disagree passionately about the means to achieve those ends, partly on the basis of their differing experiences. To rule those views out of bounds would be to rule out much of what citizens want to say and want to be heard in a deliberative system, limiting their empowered communication in unjustifiable ways. Thus a more expansive view of what makes a system democratic includes the extent that it is sensitive to all that is said in the public sphere. Whether that makes it deliberative is another question, but that is the heart of the issue: can a system be both deliberative and democratic in more than Christiano's limited sense?

An alternative approach starts by distinguishing between modes of reasoning, such as Chambers (2005: 207) who draws a line between the Socratic ratiocination of philosophers and Supreme Court justices on the one hand, and the public reason giving embodied in the publicity principle on the other, a distinction that Chambers labels 'public reason' versus 'public reason' (original emphasis). Still others focus on the narrative forms of deliberation, the primary mode that deliberators use in the real world: telling stories, helping others feel what it is to be in another's shoes, and making public claims on the basis of those experiences. ${ }^{1}$ Public reason, in this sense, is not about achieving universal objectivity; it is about figuring out what to do at a given moment for a given people with particular concerns, experiences, desires, and preferences, things that Bohman (Chapter 4) bundles into the label 'perspectives'. Public reasoning should still include reason-giving - the justification and probing of reasons behind proposals - but these reasons are often couched in terms of lessons drawn from lived experience and must be offered in terms that others can accept before they can be taken as determinative (Niemeyer 2011). Thus deliberative scholarship has come full circle, returning to Habermas's more sociological concerns in Between Facts and Norms (1996) after spending some time focused on more technical issues of institutional design and the analysis of contained moments of decision-making.

This loosening of what it might mean to 'reason together' is one of the critical intellectual moves that has allowed the deliberative systems

\footnotetext{
1 Parkinson (2006a, 138-40), with debts to Rorty (1998) and Young (2000).
} 
approach to re-emerge. Walzer's (1999: 68) criticism that '100 million [people], or even 1 million or 100,000 can't plausibly "reason together" depends on a Socratic understanding of reasoning. For what I call macro deliberative theorists, millions of people can indeed reason together if by 'reason' we mean narrating and claim-making in a way that is 'decisionoriented' (to use Chambers's term); and if by 'together' we mean 'on the same topic' and 'in the same, broad communicative system'. An important objection arises: that by redefining public reason in this way, macro deliberative theorists have thrown the deliberative baby out with the bath water. If everything is deliberation, then deliberation means nothing any more, and contributes nothing to our understanding of democracy: deliberation risks becoming 'directionless, or worse, pointless' (Bächtiger et al. 2010: 48). Now, that objection is clearly overstated in this form. The 'reasons' criterion filters out a great deal of everyday talk (Niemeyer 2011), but it does not remove problems of insincerity and manipulation, so a modification of the objection still stands.

Chambers suggests that a way of distinguishing deliberation from mere talk is that the former needs to be 'decision-oriented', but that does not address the objection either. Instead, one might apply Bohman's analysis (Chapter 4) to argue that the objection misses the point of the systemic turn. A system with a division of labour is deliberative to the extent that it increases the pool of perspectives, claims, narratives, and reasons available to decision-makers, and whether those perspectives are generated deliberatively or not is neither here nor there so long as the decision-makers' processes themselves are deliberative - and this is indeed the line that Bächtiger et al. (2010) take, distinguishing between communication that is an input into deliberation and deliberation itself (see also Parkinson 2006a: 171). Thus Chambers is right to argue that public opinion research, something that is not itself deliberative, can be an important input into a deliberative system if it provides a channel for the perspectives of those who have no other channel. Similarly, Mansbridge et al. (Chapter 1) can argue that the openly partisan and clearly interested play an important role in a deliberative system when they alert citizens to issues and increase the pool of available perspectives, increasing the system's overall deliberative quality, without needing to claim that this represents the sum total of deliberation in a system.

Here I want to raise the first of my caveats. In the real political world, decision-makers make decisions to trust others to come up with quality inputs into their processes, just as citizens do. Following MacKenzie and Warren (Chapter 5), those judgements are made on the basis of assessments about the participants' motivations and competence. This has an important side-effect: perspectives that have been generated by more reliable 
technologies weigh more in public deliberation than those that have not. Here, 'reliable' means processes that are likely to be free of the distortions of instrumental rationality that have long exercised public managers, including narrow self-interest and cognitive limits on knowledge (Simon 1947; Papadopoulos, Chapter 6) - i.e. bad motivations and limited competence. Furthermore, there is a hierarchy of technologies, with unmanaged public discourse near the bottom, qualitative social science higher, survey research further up, deliberative minipublics higher still, and so on. Where economics, lobbying, constituency views, and party members come in that hierarchy varies by setting.

The result is that not every contribution to the pool of perspectives is treated equally. Contributions are sorted into reliable (good motivations and competence), unreliable (poor motivations and competence), and mixed. Indeed, it may be that the deliberative turn makes equality less likely in such a context: one of the reasons why some advocates of deliberative minipublics have been promoting them (eg. Fishkin 2009), and why the British government in particular took to minipublics with such fervour in the mid- to late-1990s, is because they promised a competent, disinterested public voice rather than an ill-informed or partisan public voice. ${ }^{2}$

This is crucial. Christiano's account aside, the democratic credentials of a deliberative system rests on the degree to which it includes all perspectives equally (see Mansbridge et al., Chapter 1: xx). If deliberation itself introduces features into a communicative system that ensure that perspectives are not treated equally, then the deliberative systems approach is doomed to failure. The riposte to Walzer's (1999) 'reasoning together' objection seems to include the seeds of its own undoing.

Bohman and Chambers both offer a normative way out. For Bohman, a good deliberative system is one in which there is a plurality not just of inputs but of kinds of input, and that those kinds are treated with equal respect. It is not that we should sort the pool of perspectives into a hierarchy according to the mechanisms that generated them, but that we should (1) use a variety of mechanisms to ensure that we have increased our pool to the widest possible extent; and (2) that each perspective is then treated on its own merits. Chambers says something similar: she emphasizes the point that epistemic quality is not the sum total of deliberative legitimacy; inclusion is important too, and mass, aggregative methods are an important way of ensuring full inclusion. MacKenzie and Warren, meanwhile, argue that it is crucial that, in their terms, there are both institutions of trust and institutions of distrust, and that judgements about when to use which are

\footnotetext{
2 Harrison and Mort (1998); Parkinson (2004); Papadopoulos (Chapter 6). See also Hogg and Williamson (2001) for a critique of the ideal of the disinterested citizen.
} 
partly based on the features of the relevant publics: where a defined public exists on a topic, then it is right to consult that public directly; where there is not, then a deliberative minipublic can be used to anticipate the reactions of publics to proposals.

At this point, my second caveat arises. The anticipatory role of minipublics is greatly overstated, because there is no such thing as a perfectly anticipatory context. Deliberation in the real world takes place in a context of power and interests (Shapiro 1999). The decisions and deliberations of real minipublics impact on established interests and preconceptions, sometimes significantly. When confronted by deliberated agreements that contradict their positions, organized interests react in three ways: by putting forward opposing perspectives; by calling into question the motivation and competence of the minipublic, often by sowing doubts about such 'quaint, think-tanky experiments', as one senior UK government policy advisor once said to me in an interview (Parkinson 2006a: 82); and by applying other kinds of political pressure via routes to which they have privileged access (see Hendriks 2002, 2006b), doing end-runs around the minipublic. Likewise, the casually observing public - the great majority frequently dismiss counterintuitive results of deliberation as the ravings of madmen. Fishkin (1997: 1-2) opens with exactly such a story about the town of Grandview from the movie Magic Town, in which deliberators come up with 'such a preposterous departure from conventional opinion that they become an object of national ridicule'. It is precisely this feature of deliberative minipublics that the opponents of abolition of the monarchy used in Australia in 1999 to undermine confidence in the motivations and competence of a deliberative poll (Uhr 2000). MacKenzie and Warren acknowledge this problem (Chapter 5, xx), as does Fishkin (1997), but do not pursue its implication, which is that the anticipatory function is most reliable on issues that lack political salience. Elsewhere, I have argued that such a lack of salience renders deliberative minipublics less attractive motivationally, and makes them less likely to attract attentive publics (let alone the inattentive), robbing them of some of their legitimating power (Parkinson 2006a).

It is worth noting here that Bächtiger et al. (2010: 49) make a related objection to the 'any old input + deliberation' solution. They argue that rational consensus and sincerity are preconditions of deliberation itself. That is, it is the expectation that a rational consensus will emerge, and the expectation that one's interlocutors are sincere, that motivates one's own deliberative behaviour. We can apply this to systems thinking as a way of restating my caveat: if decision-makers think that the pool of perspectives has been generated by those who are insincere or self-interested, then they themselves may not behave deliberatively. Bächtiger (2005) reports 
evidence of this in a micro setting; whether it applies across settings in a system is an important empirical question.

Now, one response to this caveat is to recommend institutional arrangements that minimize the ability of powerful interests to do end-runs, restricting the formal public sphere (Hendriks 2002; Parkinson 2006a: 157-8). Likewise, Papadopoulos recommends coupling minipublics and empowered decision-making sites: not so tight that the former become co-opted, not so loose that they are ignored. However, that is not the recommendation that emerges from the other contributions. Bohman, for one, recommends institutional pluralism 'in which there is a variety of overlapping and mutually checking procedures, each formulated according to its contribution to the division of decision making and epistemic labour within the deliberative system as a whole' (Chapter 4, xx; see also Mansbridge et al, Chapter 1, xx and Christiano, Chapter 2, xx on competition). However, that solution is under-specified as it stands. Once again, not all access points are created equal: some have more communicative power than others. In that case, what may be required is not just competitive pluralism, but a set of strong institutions that are both connected to the broad public sphere and empowered to perform a scrutiny and checking role - Thompson's 'tribune', for example (Thompson 1999) - as well as the media, interest groups, and citizen networks. Just as it has long been recognized that formal, small-scale deliberation works best with a trained moderator (e.g. Dryzek 1987), so it might also be the case that large-scale deliberative systems require empowered referees to control the game.

In constitutionalist democratic theory this is the role of the courts, but again Papadopoulos's objections are important here. In real-world politics, constitutionalism becomes judicialization, the shift of power away from the players to the referee and those with the resources needed to access the referee. Judicial judgements involve deliberation of a kind, certainly, but not the 'public reasoning' that was emphasized earlier in this section, and certainly not of an inclusive kind. Nor does judicial reasoning match Christiano's democratic criteria: the judiciary is drawn from a very narrow slice of society, even taking the limited exception of magistrates at the bottom of the judicial hierarchy in the UK into account. This highlights the normative importance of Christiano's 'groundedness' criterion: in a democratic deliberative system, experts and institutional power brokers should themselves come from a broad base, sharing solidarity and overlapping understanding with other citizens.

Of course, it is clearly the case that these caveats and objections are mainly to do with the implementation of deliberative ideals in an imperfect world, and thus do not necessarily tell critically against the norm itself although see Gunnell (1986) for a sustained critique of the separation of 
theory and practical politics. But it might just be the case that it is impossible to make abstract judgements about what kinds of reasoning count in a deliberative system. This is the final possible response to the challenge posed at the start of this section. As Mansbridge et al. argue, partisanship and self-interest might be destructive of the deliberative system in some instances but constructive in others, just as numerous political theorists over the years have argued that some situations call for suits and sober miens, while others require throwing the toys out of the cot (Parkinson 2006a). I, and I suspect many other deliberative democrats, feel somewhat uncomfortable making such a recommendation, because at the end of the day the deliberative movement, if we can call it that, is in large part about replacing power plays and political tantrums with 'the mild voice of reason' (Bessette 1994). Not only that, but deliberative democrats, deep down, judge deliberative systems by their substantive outcomes as much as their procedures. Political legitimacy involves not just doing things right, but doing the right things (Beetham 1991; Chambers 1996; Parkinson 2003).

This points in the direction of refinement to this solution, one that comes from Fung (2005). In brief, Fung's view of deliberation 'before the revolution' is that unreasonable acts are justified to the extent that political circumstances are unequal, and failures of reciprocity abound. In other words, talk first, but if one meets a stone wall, ramp up the pressure until one is heard, and feels heard. ${ }^{3}$ This fits with Chambers's point: public opinion is a valuable input into the deliberative system if - and only if - there are failures elsewhere in the system that mean it is the only way for some voices to be heard. So, a deliberative system is more democratic when it hears what (the inclusive) people say - that it takes their communication seriously - but that in an imperfect context it may (often) be necessary that people try different means of communicating, even deliberately disruptive means, before decision-makers start listening. It is yet more democratic when the decision-makers themselves are authorized and accountable, or chosen in a random way that improves judgements about good motivations and thus trust.

This is not a general, non-specific pluralism; it is a stepped pluralism. It has a default setting - reason together calmly, à la Bessette (1994) and Gutmann and Thompson (1996) - but it also has different communication channels and modes appropriate to a given context, with referees and Christiano's 'groundedness' requirement. It is also a pluralism with formal decision-making sites that are accountable, either electorally or

\footnotetext{
${ }^{3}$ Readers familiar with game theory will recognize the echoes of Axelrod's (1981) 'cooperate, then tit-for-tat' strategy in this formulation: first 'cooperate', but if the response is 'defect', then 'defect' in turn.
} 
deliberatively (Roche 2003), to the rest of the public. This, I think, is one good response to the problem of democratizing reason in real deliberative systems. 'Deliberation' on this account still has some analytic bite - it is not all things to all people - but it becomes a means to an end rather than an end in itself. Sometimes non-deliberative means will be required in order to make the deliberative system as a whole more responsive. Whether that is a sufficient response will be seen shortly.

\section{Responsiveness, determinacy, and communication}

The word 'responsive' in the last section brings us to the next set of democratic challenges for a deliberative systems account. For some theorists, the democratic credentials of a deliberative system rest on the 'responsiveness rule' (Goodin 2003b; May 1996; Saward 1998). Christiano (Chapter $2, \mathrm{xx})$ takes a variant of this line, claiming that a system is democratic to the degree that it 'faithfully implements the basic aims of citizens'. At the same time, it has been a standard line in democratic theory that systems are democratic to the extent that public wishes are determinative in some way. If consulting public opinion is a merely formal requirement, but government action is actually driven by powerful interests, then we do not have democracy (Beetham 1994; Dryzek 1996; Papadopoulos, Chapter 6). Furthermore, all the classic electoral definitions of democracy have a simple mechanism for handling disagreement: majority rule. While some deliberative accounts also have a determinacy requirement (e.g. Cohen 2007; Thompson 2008a), others do not. Indeed, in the early phases of deliberative theory it was a standard criticism that deliberative democrats had no account of decision-making at all, let alone a decision rule, once the highly problematic consensus requirement was watered down or dropped entirely (Dryzek 2000). For some years now, most scholars have therefore thought that deliberative democracy must be a system of 'talk, then vote' (Chambers, Chapter 3; Goodin 2008).

But the deliberative systems approach throws this into question once more, thanks to the very moves it makes to open up what counts as reasoning together. In electoral democracy, the link between citizens' preferences and electoral decisions is relatively direct: although mediated by the party and electoral systems, voters' choices determine the outcome. In classic deliberative democracy, citizens' preferences are constructed in deliberation - they do not pre-exist it - and so the idea that there is a gap between initial preferences and outcomes simply does not arise (List and Koenig-Archibugi 2010). But in deliberative systems, at least as articulated here, there need be no direct link between citizens' perspectives and outcomes. Nor could there be: only a small number of citizens are going to 
have well-formed and well-informed preferences on any given topic, which is one of the reasons why there is a division of labour and a need for institutions of trust in the first place. The great mass of people are going to have bits of argument and bits of experience, many of which will compete with each other. Some participate only minimally, trusting others to do it maximally; some contribute only in the form of aggregate data in opinion surveys; others may have come to conclusions in one corner of the deliberative system that are at odds with the conclusions reached in another. It is the role of decision-makers (elected, randomly selected, or self-appointed) in empowered sites (whether traditional assemblies or democratic innovations, as in Smith 2009) to put the pieces together into a coherent whole, leaving out some pieces and reconfiguring others in order to resolve disagreements. So there is always going to be a gap between opinions and preferences in the broader public sphere and the agreements that deliberative systems deliver a degree of indeterminacy about public opinion. Can the deliberative systems approach bridge that gap?

There are several different ways of attacking this problem. We might think that responsiveness is the right criterion, but that the system should respond to the common good, or to citizens' expressed aims (Christiano, Chapter 2), or to preferences that have been 'laundered' in deliberation itself (Goodin 1986) rather than to perspectives or raw preferences. I have already distanced myself from the 'aims' formulation, and 'the common good' is not a terribly effective evaluative standard because in most cases it is something that is discovered or created in deliberation, not an external, pre-existing standard against which we judge deliberation (Parkinson 1999; cf. Estlund 1993). The laundered preferences response simply restates the problem - citizens need to be able to recognize the laundered results and, as already discussed, there are reasons to doubt that would happen in the real world.

Another response might be to extend MacKenzie and Warren's (Chapter 5) analysis and argue that responsiveness is the wrong criterion, and that trust is a better central principle. As use makes them familiar, citizens will come to trust that minipublics, minidemoi (Bohman, Chapter 4), or other small-scale deliberative processes are the right way to solve political controversies, and so any correspondence between their wishes or perspectives and the outcome does not matter. What matters instead is that the system be systematically sensitive to citizens' inputs - i.e. back to the account of democracy in the previous section. We should then want the institutions of a deliberative system to be organized in such a way as to give citizens good reasons for trusting decision-makers based on assessments of motivations, competence and, crucially, respect, adding to that institutions of distrust in which those assessments are carefully and publicly scrutinized. 
But surely it is problematic to rely on institutions of trust in democratic contexts where trust in all sorts of institutions is declining (Papadopoulos, Chapter 6). One might argue that the institution itself will create trust; but trust in MacKenzie and Warren's exemplars of trusted institutions - legal juries - is also declining. Although it is easy to forget this in moments of institutional crisis, it is not just the design of political institutions that is causing a loss of trust, but fundamental shifts in technology and the citizenry as well. All over the world, citizens are better educated, more informed, more critical, and less deferential. They not only have access to better information, they are themselves the producers of information, and are therefore much more likely to rate their own information processing abilities more highly than the abilities of those who produce what to them are counterintuitive results. It seems unwise to put all, or even a significant proportion, of the democratic burden on institutions whose social and psychological foundations are being eroded.

Still another response is to take more seriously the 'social decisions' point made by Mansbridge et al. (Chapter 1), and this is a response in which the changing nature of citizens' interaction with each other and with power is a positive feature rather than a negative. The idea here is that the broad fields of citizens' decision-oriented discourse in the public sphere often not always, but often - acts as a significant driver of and constraint on formal decision-making. Rae (2003: x), in his preface, gives an excellent account of how this feels from inside local government, which is relatively weak in the face not just of the usual array of interests, agencies, and representatives but "forces" as ineffable as popular culture - from its veneration of green lawns on quiet streets to its hypnotic fascination with firearms [which] form part of the power environment in which city government must operate'. One of the clearest accounts of how these 'ineffable' forces can be democratized comes from Dryzek (1990, 2000, 2006), who uses examples of decentred, flat-structured, diffuse yet participatorily controlled social networks to show how citizens can be not just the unthinking mass-generators of discourse but the reflexive, critical, deliberative creators of discourse. His normative yardstick for a democratic deliberative system is one in which agreements come about through the contestation of such reflexive discourses. Now, of course, Dryzek is not so naïve as to believe that all discursive contestation in real politics is conducted in this reflexive way; but he does believe that important strands of modern politics can be understood in this way, particularly the environmental and anti-globalization movements.

One of the traditional weaknesses of such approaches is that they lack a clear account of how that contestation is translated into acts of governance. Habermas (1996) has provided one such account, with his 'two track 
model' in which opinions formed in the informal public sphere are translated into law in the formal public sphere by mediating institutions like minipublics, the news media and social networks, and automatically by virtue of the fact that decision-makers are themselves participants in discursive contestation. But this can mean that the precise linkages between discussion and action are opaque to citizens, and thus open to manipulation by powerful insiders (Papadopulos, Chapter 6). Compared with aggregative processes, in which there is a clear story about how individual preferences are added together to choose governments; and compared with MacKenzie and Warren's or Christiano's proposals, where there are publicly visible sites for deliberation, discursive processes are much harder to pin down. It is hard to hold anyone to account for their actions and reasons, hard to judge the presence of hidden agendas and interests, and hard to judge the strength of support for a proposal if there are no clear sites of power, no clear lines of responsibility and accountability, and no clear institutional boundaries. ${ }^{4}$

Dryzek himself has come up with a modest proposal for a transmission mechanism, the 'chamber of discourses', in which discourse representatives are chosen by means of a social scientific procedure, the $Q$ methodology. ${ }^{5}$ I am not a fan of the chamber of discourses approach: its highly technical selection method is too opaque to allow citizens to make good trust judgements. But there are many, many more options available than just that, and some of them are both familiar and fit the need for decisiveness. Most obviously there is the referendum device, which can be used to send precise proposals (rather than more-or-less vague problem statements) to the people for a vote when other institutions have not been able to reach an agreement. The referendum process has many anti-deliberative features, especially when used as an agenda-setting tool or when it is expected to reveal consensus among citizens that is lacking among representatives (Parkinson 2001, 2009). However, when used to legitimate a course of action, they are useful indeed because of their broad franchise and (ideally) decisive force. This is one of the features of the British Columbia Citizens' Assembly (BCCA) case that is not given enough discussion. Writers citing the case tend to focus on the Assembly itself, forgetting the referendums that followed and all the communication that surrounded the decision over more than five years. And yet the interesting features of the case from a democratic point of view is that the Assembly made no binding collective decision; the decision was made by citizens in

\footnotetext{
${ }^{4}$ March and Olsen (1995); Savoie (2004). For an extended argument for the importance of single, physical stages for democratic scrutiny and accountability, see Parkinson (2012).

${ }^{5}$ Dryzek and Niemeyer (2008). On Q methodology, see Brown (1980).
} 
two referendums, one in 2005 and another in 2009 (Carty et al. 2009). So while the BCCA itself was not decisive, and had no direct responsiveness mechanisms, the system as a whole was. Smith (2009) notes other benefits of the referendum device in a deliberative context (see also Budge 1996), along with several other 'innovations' which connect the informal public sphere with empowered decision-making moments.

Dryzek (2009) has also argued that participation in minipublics is itself a tool of democratization, because it builds the capacity to exercise communicative freedom and power (to use Bohman's terms) in other spheres as well, a variant of the spillover thesis long advocated by participatory democrats from Pateman (1970) to Mansbridge (1983) and on (e.g. Gastil et al. 2010; see also Carter 2006). In other words, small-scale deliberation can have large-scale impacts not just in a formal, mechanistic way, but because it helps to create the very kinds of empowered citizens that make discursive democracy at the large scale work (Goodin and Dryzek 2006). Those empowered citizens then choose their fights in an active fashion. Thus democracy could be enhanced in a deliberative system not just by mechanisms that hard-wire linkages between the formal and informal public sphere, but also by a plurality of participatory institutions that encourage active citizenship - an active citizenship that demands responsiveness in a bottom-up fashion rather than a formal, institutional design approach that generates responsiveness in a top-down fashion.

This might well be right, but it cannot be sufficient. The same objections that arose with regard to radical pluralism in the previous section apply again here. A final response is to have a more nuanced view of what representation in a deliberative system demands. Representation scholarship has recently undergone something of a revival and recasting after being stuck for many years in the highly influential but problematic analytics of Pitkin (1967). From Young (2000) and Urbinati (2000), to Mansbridge (2003), Rehfeld (2005), and Saward (2010), representation theory now emphasizes both 'representation as relationship', to use Young's term, and the idea that constituencies are not fixed entities determined by identity and borders but are fluid things called into being by representative claims (see also Bohman 2007; Iveson 2007; List and Koenig-Archibugi 2010). These two moves transcend the limits of traditional principal-agent thinking, in which the problems of responsiveness are cast as difficulties of identifying fixed, pre-existing constituencies and knowing what they want, and creating bonds of authorization and accountability such that representatives do those things. Instead, representatives call constituencies into being by their claims - appeals to 'right thinking people' or 'urban youth' - such that citizens identify and engage with different representatives on different topics in different contexts. This is both more normatively 
useful and more empirically accurate. Empirically, partisan dealignment has been a long-noted phenomenon, with citizens supporting more specific causes, perspectives, and arguments rather than simply identifying with or deferring to party lines or members of parliament. ${ }^{6}$ Normatively, it helps us see responsiveness as a matter of mutual, co-creation of perspectives and problems between citizens and representatives, even where decision-making power is delegated to trusted institutions. The problems then become ensuring not that representatives do as they are told, but that representatives are grounded in and give voice to the wide variety of perspectives that might be relevant on any given topic (Christiano, Chapter 2; Young 2000: 148).

This view of representation helps reconcile the deliberative ideal that citizens' views are created in deliberation with the systemic approach that creates a deliberative division of labour, because rather than seeing deliberative authenticity as being either a top-down or a bottom-up affair, it sees it as both, and shares the responsibility between citizens and representatives. But we should not think that the problems of responsiveness and determinacy magically vanish in such a conception. As discussed in the previous section, and as Chambers insists at the end of her chapter, it needs to be remembered that sometimes raw opinion reflects 'what citizens actually think, believe and care about'. This means that despite the best communicative efforts of representatives and citizens, there is always going to be some gap between demands and outcomes in a deliberative system. Thus while a revised account of representation means that Papadopoulos's concerns about formal bonds of authorization and accountability are probably overstated, they are not irrelevant.

Caveats three and four arise at this point. Number three is if deliberative systems theory is going to place the democratic burden on communication between representatives and citizens, then there needs to be a very great deal more work done by deliberative democrats to understand the channels of communication. In a complex society, the burden of communication between citizens and representatives is going to be carried in three ways: face-to-face or one-to-one, in relatively small networks; via the traditional mass media; and via online social networks, some of which are large-scale, some of which are quite small.

${ }^{6}$ For a critical review of dealignment in the UK context, see Dunleavy (2005). This is not to say that identity issues are unimportant, especially when it comes to the recursive and rhetorical construction of identities: 'right-thinking people' and 'patriots', or 'urban youth' and 'hard-working families'. Perhaps one blind spot of some new representation theory is that it does not take the performative and rhetorical construction of representation seriously enough, with the notable exception of Saward (2010: 66-70). 
Deliberative democrats have long recognized the limitations of face-toface engagement, although part of the point of the deliberative systems approach is to reactivate interest in the myriad conversations around kitchen tables and online that make up the informal deliberative system (Chambers, Chapter 3; Jacobs et al. 2009; Mansbridge 1999; Mansbridge et al., Chapter 1), while others have pointed out the benefits of deliberative enclaves for subaltern groups (Fraser 1992; Sunstein 2002). However, deliberative democrats continue to present an unrealistically rosy view of both traditional and new media, treating both as perfect transmission mechanisms instead of institutions that have incentives and filters, like any other institution. The traditional media introduce systematic distortions into deliberative systems: even putting aside 'pre-revolution' (Fung 2005) problems with the political economy of news, their audience and narrative requirements, and physical features mean that the personalistic, unusual, and conflictual dominates over the impersonal, the usual, and the harmonious, while much of the story that deliberative democrats want to tell fall into the latter category, not the former (Parkinson 2006b). This introduces incentives to focus on the dramatic features of an issue at the expense of the more mundane. Certainly the traditional media are good at conveying 'perspectives', and if that is all we judge the quality of deliberative systems by then the problem is relatively minor. However, that is not all we judge deliberative systems by: we also want them to be good at communicating reasons for agreements, and details about macro-political forces. This means that the problem is still significant. Research on the deliberative quality of social media, meanwhile, is still in its infancy, with analysis focusing largely on micro-deliberative criteria rather than systemic inputs (Janssen and Kies 2005; Wright and Street 2007; although a partial exception is Hajer 2009). Again, there are reasons to be cheerful: citizen-journalists are now much more effective at communicating perspectives and telling stories that traditional media, for various reasons, do not cover well; or, as in the Arab Spring, set the agenda for traditional media, formal institutions, and informal deliberation alike. But there are also reasons to be extremely cautious, to do with the loss of civility that occurs online; the tendency for online communication to strip situations and arguments of their subtleties; the increasing technical ability of the powerful to restrict content and dialogue online, given the dependence of online networks on hardware that is outside the network members' control; and the very proliferation and fragmentation of media that makes it relatively easy to reach particular groups but much harder to reach citizens in general without significant resources and without significant resources going into attracting attention to a story. This is to say nothing of the rhetorical, symbolic, and 
performative tools needed to attract attention (Edelman 1988), things which lead unmediated public deliberation to be conducted in largely symbolic rather than reasonable terms (Niemeyer 2011), features which have led many deliberative democrats to be extremely wary of rhetoric. ${ }^{7}$

All this calls into question the ability of citizens and representatives not to talk but to be heard. Deliberative systems that rely on mediated communication might feature a lot of talk, but only a limited number of sites of talking together let alone reasoning together. The sites that do have desirable features might have a limited impact on the rest of the public sphere. Perhaps the best that can be hoped for in a deliberative system is that it uses lots of different channels, including a mix of face-to-face, small network, social network, and traditional media outlets; and that at least some of that communication concerns the grounds of trust between decisionmakers and publics, as well as the substantive detail of an reasons underlying agreements reached. Even that stripped-down norm demands a great deal. To return to the BCCA case, evidence reported by Thompson (2008b) suggests that more than two-fifths of respondents to a pre-referendum survey could barely recall the Assembly, if at all, just a few months after its final report was released. While the Assembly clearly had an impact on the vote of those who knew about it, large numbers were untouched. That seems disappointing in a process that is frequently held up as a paragon of macro deliberation in action.

The fourth and final caveat relates to deliberative democrats' great faith that deliberative processes result in epistemically better, procedurally better, or just decisions. There is remarkably little empirical evidence to go on here - most of it is anecdotal at best, and even that which is not is generated in the rather limited, controlled environments of minipublics (Ryfe 2005). Using that as evidence of the deliberative capacities of citizens is fine (Niemeyer 2011), and to be warmly welcomed. There is no point discussing deliberative systems if citizens do not even have the capacity to act in accordance with deliberative norms. But using that evidence to think that deliberative systems will have the same effects is just a mistake. An entirely different set of outcomes is possible under different institutional constraints (Bächtiger and Hangartner 2010). Perhaps, having opened up normative room for many different sites and modes of expression, systems come to be dominated by perspectives that are narrowly constructed, unreflective or self-interested. Perhaps the powerful just exercise power in whatever way they can. Perhaps discourses that are generated in the right

\footnotetext{
See, for example, Chambers (1996). Not all deliberative theorists dismiss the role of rhetoric, including Dryzek (2000, 2010b) and O’Neill (1998). See Parkinson (2006a: ch. 6; 2012: ch. 2) for further discussion.
} 
way have no correlation with right content. This is something that troubles students of the Tea Party movement in the US: disaffected conservatives have borrowed the grassroots and online networking techniques of the progressives to forge a more powerful anti-progressive alliance (Williamson et al. 2011).

\section{Summary: the criteria for a democratic deliberative system}

Let me sum up the tensions and implications discussed in the last two sections before offering an in-principle answer to the question that opened this chapter.

The first major point is that the deliberative systems approach is based on a loosening of what counts as 'reasoning together', based on dispersed narration and opinion generation oriented to public decisions, and making claims for public action or inaction. However, that loosening opens up room for trouble in real-world systems of governance. The normative vision calls for the equal treatment of perspectives, but introduces into real political systems a technical hierarchy, based on the very criteria that are used to make trust judgements, that ensures that perspectives are not treated equally. While the norm might seem attractive in the abstract, its effect in governance is to restrict greatly the sources that count and thus to impose its own kind of restrictions on the range of voices that can heard. It may even impact on the willingness of decision-makers to behave in accordance with deliberative norms.

Three solutions are offered, two of which are opposites. Most of the contributors to this volume recommend institutional pluralism that encourages competition between techniques and voices, while another approach is to insist on a carefully constrained formal public sphere in which deliberative norms are more strictly enforced and the number of access points is strictly limited, combined with what I have called 'stepped pluralism' in which it becomes legitimate to move away from deliberative norms the less one is treated with like regard. Perhaps it is no accident that those advocating the former are North Americans, used to a system of institutional pluralism, checks, and balances, while the latter are Europeans and Australasians, used to a more structured, controlled institutional approach. Which produces better deliberation or more legitimate outcomes, however one measures those things (Bächtiger and Hangartner 2010), is an empirical question, although I have leaned towards the 'managed' approach for reasons to do with the resources required to be effective in a pluralistic environment. The third recommendation is to ensure the groundedness of decision-makers in the perspectives they are meant to represent and adjudicate between. 
Whether equal treatment requires anything more than being treated with respect is another area of disagreement. While some kind of determinacy in deliberation seems to be required to make it democratic, the deliberative systems move makes that very difficult. The discussion began by presenting the problem as being to do with the degree to which collective decisions fitted with citizens' preferences. For the most part, deliberative theory conceives citizens' preferences as constructed in deliberation, not pre-existing it, but the deliberative systems move makes that a more problematic conception: not everyone has their preferences transformed by the 'better argument' because not everyone is exposed to all the arguments. Some participate only minimally, trusting others to do it maximally; some contribute only as aggregate data in opinion surveys. Mediated communication introduces further filters on what information people are exposed to. So there is always going to be a gap between what citizens want and what deliberative systems deliver, and yet deliberative systems need to take those wants - raw opinion, to use Chambers's phrase - seriously, not just those generated by the most sophisticated technique.

A frequent response is that the system should be responsive to laundered preferences or the contingent results of reflexive discourse, but both of these responses recreate the problem - it is an empirical question whether citizens will recognize their inputs after the laundering or grant legitimacy to the ideas of those (relatively few) reflexive discussants. I think that unlikely without a great deal of change in the broader communicative system. Another response is to argue that new institutions will create new habits, and that trust will emerge as citizens start to see deliberative forums as the right way of doing things. That presupposes a limited formal public sphere rather than a competitive pluralist one, outlined above - only the 'right kind' of institution, such as minipublics or minidemoi, are likely to generate trust on MacKenzie and Warren's account, while I have warned against relying too heavily on trust when trust in institutions generally is in marked decline.

The response that seems to work best is to think of good deliberative systems as being richly representative ones, hitched to a combination of direct and indirect decision-making institutions like referendums, minidemoi, and elected assemblies where appropriate. Representation should be an ongoing relationship based on flexible constituencies rather than a fixed, positional relationship between principals and agents. Representatives can be elected - and elected representation brings with it a kind of accountability that other modes cannot replicate (Parkinson 2006a) - but in deliberative systems representative roles can be performed by the selfappointed and the randomly selected as well, especially in settings like the international financial system where there are no formal, fully democratic 
institutions to act as focal points. The key criterion for judging representatives in a deliberative systems account is that they are 'grounded' in the experience of those they represent: that the 'pool of perspectives' available to decision-makers is broadly inclusive, and that the representatives themselves are diverse in their experiences. No one group of representatives can do this, so a good deliberative system will feature a range of sites, a range of perspectives, and a range of communicative modes along with some public decision-making mechanism. Nonetheless, to maintain its deliberative character there should be a 'default mode' of reasonable, respectful discussion which, while having more of the character of public reasoning than the Socratic mode (Type II more than Type I, in Bächtiger et al.'s terms, 2010), imposes more justificatory demands at the formal end of the public sphere, leaving the relatively powerless free to try other means when they find their claims, arguments, or agency dismissed without respectful consideration. To aid the powerless and increase the pool of perspectives there might need to be a macro deliberative moderator: perhaps Thompson's tribune or some other kind of watchdog. Marketized media do not in themselves provide the necessary diversity of perspective (Street 2001). Whether the powerful should be given the same right to turn to non-deliberative means is not something I have gone into here, but the answer is probably 'no'. One of the pathologies of deliberation (Stokes 1998 ) is when the powerful circumvent reasonable processes in order to get what they want, and as Bohman (Chapter 4) argues, one of the purposes of a deliberative system is to empower citizens against powerful interests.

This account has many points of similarity with the more state-focused, formal deliberative system outlined in Parkinson (2006a). There is no need to go into detail here, but the present account is meant to be more broadly applicable to ad hoc systems that come into being to address specific issues, as well as to state-focused, formal deliberative systems, as well as to transnational systems and more. But it is worth stressing that both schemes meet the sequencing criteria that Bächtiger et al. (2010) propose as a way of reconciling the tight rationality requirements of deliberation with the loose requirements of democracy. They do this by emphasizing the wild public sphere as the 'grounds' of any democracy, giving a role to minidemoi (noting Bohman's distinction between that and minipublics) in the technical appreciation of arguments, a service role for experts, a role for representatives of all kinds in presenting perspectives, communicating reasons, and making decisions where appropriate, with the latter decisiveness function performed by referendums where necessary.

Given all that, I think we can answer the question of whether it makes sense to talk of a deliberative democratic system in the affirmative, at least in principle. How closely real political systems match this ideal is another 
question, and the challenges of measuring the fit between theory and practice are considerable (Bächtiger and Hangartner 2010; Bächtiger et al. 2010). Focusing just on the issue of responsiveness and decisiveness, the key problem is recognizing when inputs have been treated seriously and integrated into the decision-making process. Bächtiger et al. (2010) back away from making the attempt, for good reasons, and argue for an empirical approach that examines opportunities and procedures rather than examining whether there is a substantive gap between public claims and acts of governance, while recognizing that this is a relatively poor proxy for real influence. But part of the problem here might be their positive political science methodologies. Alternative methods exist, including discursive, qualitative methods, computerized network analysis, and so on - methods that may be more interpretive but need not be less rigorous. This is not the place for a detailed methodological discussion, however - that is something for future work.

\section{Conclusion}

I want to close with some general reflections on the application of the deliberative systems approach. While they did not say this in so many words, the authors of the introduction (Chapter 1) talked of the 'larger goal of deliberation' as being to improve the legitimacy of democracy by making democratic institutions systematically responsive to reasons, not just the weight of numbers or the power of interests. The systems approach was taken up because no single institutional innovation can achieve that goal on its own. While the study of deliberation in parliaments and democratic innovations has been very rich and rewarding, it has been increasingly obvious that all institutions do their work in context. Indeed, increasingly scholars of minipublics justify those efforts not just in terms of the effects on participants or the rationalization of a particular decision-making moment, but in terms of their connections with other institutions and with systems of governance more broadly. While sometimes one comes across statements that equate deliberative democracy with deliberative polls or citizens' juries, say, few scholars now justify those institutions in isolation. It is the impacts that they have - or fail to have - on binding collective decisions that matter. Because the failures have much to do with the broader systemic context in which such innovations operate, it behoves deliberative democrats to look up from their microscopes and examine those interactions more seriously.

It is clear that some branches of academic deliberative scholarship are looking up, and have been looking up for some time. It is not so clear that practitioners are doing the same. For example, a deliberation industry has 
sprung up (Hendriks and Carson 2008) which, while having some features that are broadly positive for the future of deliberative democracy, have some damaging ones as well. Not the least of these is the tendency to reduce deliberative democracy to a consultants' toolkit of trademarked techniques rather than something grounded in the public sphere. In government, Papadopoulos alerts us to the fact that deliberation becomes just another tool of depoliticization, the attempt to take the politics out of politics and replace it with impersonal analysis, treating people as mere bearers of values with an uncertain grasp of facts rather than citizens with the agency and cognitive abilities that allow them to practise selfgovernment.

If deliberative democracy is a normative, emancipatory project - and the authors in this volume have certainly presented it as such - then such considerations matter. The approach needs to consider not just the questions of how citizens might deliberate together in a differentiated system, but how that system is itself embedded in a political economy, in an administrative system, in a culture, in ideologies, power relations, and interests. It is one of the strengths of this volume that the contributors are aware of these constraints, although only just beginning to think through responses that are not just analytically satisfying, but workable in the real world.

There are three next steps. The first is to subject the framework to critical scrutiny, although I would caution against the view that finding contradictions necessarily condemns the entire project to the dustbin. All our political ideals have tensions; a tidy ideal is one whose adherents have forgotten something important, usually something human. The second task is to take up the empirical challenges that have been presented, deepening our understanding of macro deliberative realities and possibilities. The third step is to take good quality empirics and build them back into the theory.

One of two broad conclusions will result: the deliberative systems approach is hopelessly contradictory and utopian on both principled and practical grounds; or it offers a way forward both as a framework of analysis and as a practical vision of how democratic societies should work. This volume has, I hope, demonstrated that the approach has some analytic usefulness, although there is much work to be done to make that demonstration more robust. As for its success as a practical vision, it would be easy to make some wearily cynical remark to close, but that would be neither justified nor helpful. We already know that, even though Habermasian ideal discourse is an extremely demanding ideal, there are islands of rational discourse in the ocean of everyday praxis (Habermas 1983; cited by Bächtiger et al. 2010: 37). Even were the majority of real deliberative systems found to be not terribly deliberative nor terribly democratic, it might be that scholars find examples of reasonably good practice, all things considered. 
Perhaps those islands are more likely to be found in small communities rather than the very large, or perhaps the opposite is true. Perhaps the state provides an essential focal point for deliberative democracy, or perhaps states are too entangled with inimical powers to be as deliberative or democratic as other kinds of system. The point is, we do not know yet. We have an analytic framework, and we have bits of evidence. Now is the time to systematize what we know, and start filling in the gaps. 